University of Wollongong

Research Online

Australian Institute for Innovative Materials -

Papers

Australian Institute for Innovative Materials

$1-1-2012$

The synthesis of lamellar nano MgB2 grains with nanoimpurities, flux pinning centers and their significantly improved critical current density

Zongqing $\mathrm{Ma}$

Tianjin University, zqma@uow.edu.au

Yongchang Liu

Tianjin University

Qi Cai

Tianjin University, caiqi6406608@163.com

Follow this and additional works at: https://ro.uow.edu.au/aiimpapers

Part of the Engineering Commons, and the Physical Sciences and Mathematics Commons

Research Online is the open access institutional repository for the University of Wollongong. For further information contact the UOW Library: research-pubs@uow.edu.au 


\title{
The synthesis of lamellar nano MgB2 grains with nanoimpurities, flux pinning centers and their significantly improved critical current density
}

\author{
Abstract \\ MgB2 superconductors with unique microstructures were rapidly fabricated at low temperatures, and \\ exhibited significantly improved critical current density (Jc). According to the microstructure \\ observations, the prepared samples consisted of lamellar nano MgB2 grains with many embedded \\ nanoimpurities (about $10 \mathrm{~nm}$ ). The formation of these lamellar nano MgB2 grains is associated with the \\ presence of a local Mg-Cu liquid at sintering temperatures as low as $575^{\circ} \mathrm{C}$. The ball milling treatment of \\ the original powders also plays a positive role in the growth of lamellar grains. Based on an analysis of \\ the relationship between resistivity and temperature, the lamellar nano MgB2 grains in the prepared \\ sample possess better grain connectivity than the typical morphology of MgB2 samples prepared by \\ traditional high-temperature sintering. Furthermore, the presence of many nano MgB2 grain boundaries \\ and nano impurities in the prepared sample can obviously increase the flux pinning centers in accordance \\ with the analysis of flux pinning behavior. Both factors mentioned above contribute to the significant \\ improvement in $\mathrm{Jc}$ from low field to relative high field. The method developed in the present work is an \\ effective and low-cost way to further enhance $\mathrm{Jc}$ in MgB2 superconductors across a wide range of \\ applied magnetic fields without using expensive nanometer-sized dopants. The Royal Society of \\ Chemistry 2012.
}

\section{Keywords}

mgb2, grains, flux, pinning, centers, nanoimpurities, their, synthesis, significantly, improved, critical, current, density, nano, lamellar

\author{
Disciplines \\ Engineering | Physical Sciences and Mathematics
}

\section{Publication Details}

Ma, Z., Liu, Y. \& Cai, Q. (2012). The synthesis of lamellar nano MgB2 grains with nanoimpurities, flux pinning centers and their significantly improved critical current density. Nanoscale, 4 (6), 2060-2065. 


\title{
The synthesis of lamellar nano $\mathrm{MgB}_{2}$ grains with nanoimpurities, flux pinning centers and their significantly improved critical current density
}

\author{
Zongqing Ma, Yongchang Liu* and Qi Cai \\ Received 7th December 2011, Accepted 26th January 2012 \\ DOI: $10.1039 / \mathrm{c} 2 \mathrm{nr} 11930 \mathrm{~g}$
}

\begin{abstract}
$\mathrm{MgB}_{2}$ superconductors with unique microstructures were rapidly fabricated at low temperatures, and exhibited significantly improved critical current density $\left(J_{\mathrm{c}}\right)$. According to the microstructure observations, the prepared samples consisted of lamellar nano $\mathrm{MgB}_{2}$ grains with many embedded nanoimpurities (about $10 \mathrm{~nm}$ ). The formation of these lamellar nano $\mathrm{MgB}_{2}$ grains is associated with the presence of a local $\mathrm{Mg}-\mathrm{Cu}$ liquid at sintering temperatures as low as $575^{\circ} \mathrm{C}$. The ball milling treatment of the original powders also plays a positive role in the growth of lamellar grains. Based on an analysis of the relationship between resistivity and temperature, the lamellar nano $\mathrm{MgB}_{2}$ grains in the prepared sample possess better grain connectivity than the typical morphology of $\mathrm{MgB}_{2}$ samples prepared by traditional high-temperature sintering. Furthermore, the presence of many nano $\mathrm{MgB}_{2}$ grain boundaries and nano impurities in the prepared sample can obviously increase the flux pinning centers in accordance with the analysis of flux pinning behavior. Both factors mentioned above contribute to the significant improvement in $J_{\mathrm{c}}$ from low field to relative high field. The method developed in the present work is an effective and low-cost way to further enhance $J_{\mathrm{c}}$ in $\mathrm{MgB}_{2}$ superconductors across a wide range of applied magnetic fields without using expensive nanometer-sized dopants.
\end{abstract}

\section{Introduction}

The superconductivity at $39 \mathrm{~K}$ discovered in $\mathrm{MgB}_{2}$, a chemical of simple binary composition, has attracted much interest in techniques for its fabrication and practical application., ${ }^{1,2}$ However, the critical current density in $\mathrm{MgB}_{2}$ is still small compared to expectations for an optimized material. Flux pinning and grain connectivity are the critical factors determining the performance of $J_{\mathrm{c}}$ in type II superconductors. In order to obtain practical $\mathrm{MgB}_{2}$ superconductors, a variety of processing techniques have been investigated to improve $J_{\mathrm{c}}$ in $\mathrm{MgB}_{2}$ superconductors, including irradiation, ${ }^{3,4}$ chemical doping ${ }^{5-11}$ and ball milling. ${ }^{12-15}$ Among them, nano $\mathrm{SiC}$ doping has proved to be the most effective way of improving $J_{\mathrm{c}}$, especially at high fields. ${ }^{6,8}$ In general, the techniques mentioned above have focused on enhancing flux pinning by engineering grain boundaries or introducing nano-impurities and lattice defects, but have tended to neglect and even impair the associated issues of connectivity, which limits further improvements in $J_{\mathrm{c}}{ }^{16}$ As a result, it makes sense to develop an effective way of both improving the grain connectivity of $\mathrm{MgB}_{2}$ and increasing flux pinning centers with the specific aim of further enhancing $J_{\mathrm{c}}{ }^{2}$

Tianjin Key Laboratory of Composite and Functional Materials, School of Materials Science \& Engineering, Tianjin University, Tianjin 300072, P R China. E-mail: licmtju@163.com; Fax: +86-22-87401873; Tel: +8622-87401873
According to the theory of type II superconductors, grain connectivity and flux pinning in $\mathrm{MgB}_{2}$ are both closely related to the micro-morphology of $\mathrm{MgB}_{2}$ grains. Thus optimizing the morphology of $\mathrm{MgB}_{2}$ grains by means of developing new manufacturing techniques is a possible approach for further improving $J_{\mathrm{c}}$.

In the present work, $\mathrm{MgB}_{2}$ samples with unique microstructures, i.e., lamellar nano $\mathrm{MgB}_{2}$ grains containing many homogeneously embedded nanoimpurities, were rapidly synthesized by ball milling and subsequent $\mathrm{Cu}$-activated sintering at low temperature. They were shown to exhibit significantly improved $J_{\mathrm{c}}$. In particular, the value of $J_{\mathrm{c}}$ in the prepared $\mathrm{MgB}_{2}$ sample was more than $1 \times 10^{5} \mathrm{~A} \mathrm{~cm}^{-2}$ at $2 \mathrm{~T}, 20 \mathrm{~K}$, which is much higher than that of typical pure and nano $\mathrm{SiC}$ doped $\mathrm{MgB}_{2}$ sample sintered at high temperature and basically meets the need of practical applications at this field.

\section{Experimental}

Mg powder (99.8\% purity, $100 \mu \mathrm{m}$ in size), amorphous B powder (99\% purity, $25 \mu \mathrm{m}$ in size) and $\mathrm{Cu}$ powder $(99.9 \%$ purity, $3 \mu \mathrm{m}$ in size) were mixed in a molar ratio of $\left(\mathrm{MgB}_{2}\right)_{0.97} \mathrm{Cu}_{0.03}$. Then tungsten carbide milling balls and the mixed powder were put into a tungsten carbide vessel with a ball-to-powder-weight-ratio of $5: 1$ in an argon box. High energy ball milling was performed on a SPEX 8000M mill under an argon atmosphere. The powders after milling for $5 \mathrm{~h}$ and $10 \mathrm{~h}$ were characterized by X-ray diffraction (XRD) in the Bruker D8 Advance X-ray 
diffractometer, respectively. Then the milled powder was pressed into a flake under a pressure of $5 \mathrm{MPa}$ and sintered at $575^{\circ} \mathrm{C}$ for 5 $\mathrm{h}$ under high purity flowing argon $\left(99.99 \%, \mathrm{O}_{2}<10 \mathrm{PPM}\right)$. The phase evolution during the sintering process was detected by an in situ X-ray diffractometer. As a reference, an undoped $\mathrm{MgB}_{2}$ sample without milling was also prepared by traditional sintering at $850{ }^{\circ} \mathrm{C}$ for $0.5 \mathrm{~h}$ under high purity flowing argon. Then the microstructure of all the sintered samples was observed using scanning electron microscopy (SEM) and high-resolution transmission electron microscopy (TEM). The temperature dependence of resistivity in the sintered samples was investigated by a DC four-probe method. Finally, the magnetization of the sintered samples was measured using a physical property measurement system. Then the $J_{\mathrm{c}}$ was calculated from the width of the magnetization hysteresis loops $(\Delta M)$ based on the extended Bean model.

\section{Results and discussion}

Fig. 1 shows the XRD pattern of the original $\mathrm{Mg}+\mathrm{B}$ mixed powder and $\mathrm{Mg}+\mathrm{B}+3 \% \mathrm{Cu}$ powder after milling for different times. It can be seen that $\mathrm{Mg}$ is the main phase in the original and the milled powder. As milling time increases, the intensity of the $\mathrm{Mg}$ peaks gradually decreases and their corresponding widths broaden, which is mainly attributed to grain refinement and accumulation of micro-strain resulting from ball milling. During ball milling, it is very easy for $\mathrm{Mg}$ to be oxidized. ${ }^{14,15}$ The suppression of powder oxidation should be considered when the ball milling technique is applied. In the present work, no obvious oxide peaks $\left(\mathrm{MgO}, \mathrm{CuO}\right.$ or $\left.\mathrm{B}_{2} \mathrm{O}_{3}\right)$ are observed, as shown in Fig. 1. This means that the oxidation of powder is well suppressed during the milling process due to the argon protection.

Fig. 2 illustrates the in situ phase evolution during sintering of the original and milled powder at $575{ }^{\circ} \mathrm{C}$. In the in situ XRD pattern of the reference sample without milling or addition of $\mathrm{Cu}$, a lot of residual $\mathrm{Mg}$ peaks can be recognized, which implies that the reaction between $\mathrm{Mg}$ and $\mathrm{B}$ is not complete even after sintering for $5 \mathrm{~h}$ (see Fig. 2a). This result is consistent with previous studies. ${ }^{17,18}$ Actually, the reaction between $\mathrm{Mg}$ and $\mathrm{B}$ at low

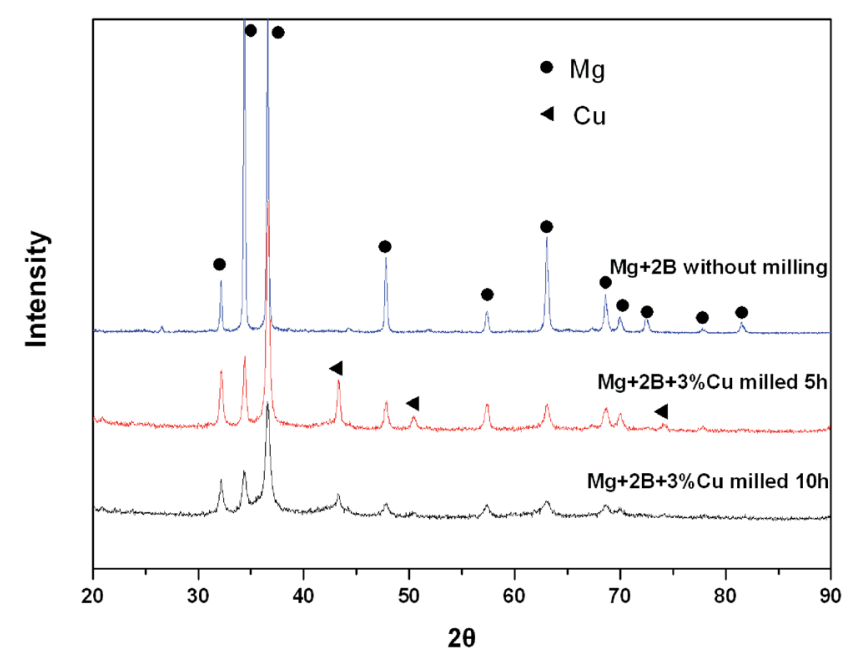

Fig. 1 The XRD pattern of original $\mathrm{Mg}+\mathrm{B}$ mixed powder and $\mathrm{Mg}+\mathrm{B}$ $+3 \% \mathrm{Cu}$ powder after milling for different times.
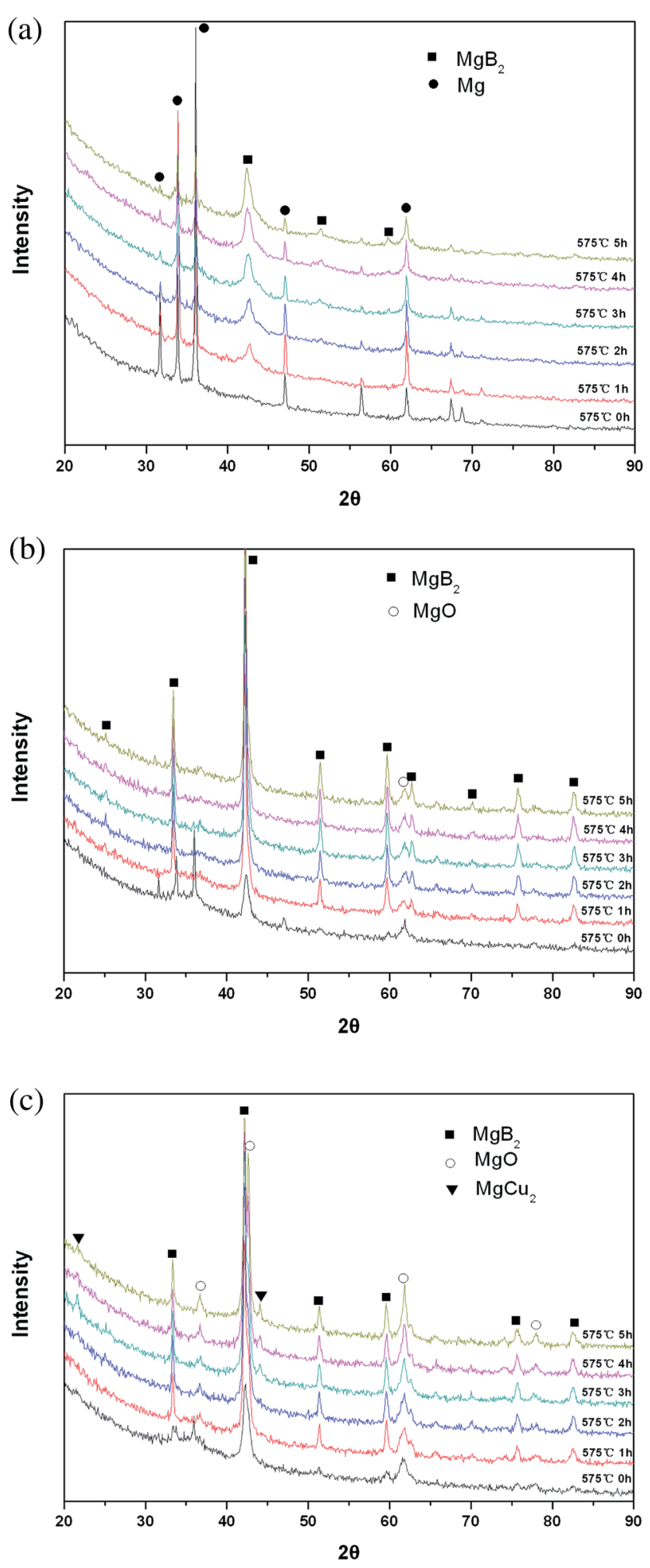

Fig. 2 The in situ phase evolution during the sintering of the original and milled powders at $575{ }^{\circ} \mathrm{C}$ with (a) original powder, (b) $5 \mathrm{~h}$-milled $\mathrm{Mg}+$ $\mathrm{B}+3 \% \mathrm{Cu}$ powder and (c) $10 \mathrm{~h}$-milled $\mathrm{Mg}+\mathrm{B}+3 \% \mathrm{Cu}$ powder.

temperatures takes a very long time to form a complete $\mathrm{MgB}_{2}$ phase as a result of the low diffusion rate of atoms in the solid state below the melting point of $\mathrm{Mg} \cdot{ }^{18,19}$ On the other hand, the formation of a complete $\mathrm{MgB}_{2}$ phase is almost complete in the 
milled $\mathrm{MgB}_{2}$ sample by Cu-activated sintering for only $2 \mathrm{~h}$. In our previous studies, the addition of $\mathrm{Cu}$ was reported to accelerate the formation of the $\mathrm{MgB}_{2}$ phase during low-temperature sintering by the presence of a local $\mathrm{Mg}-\mathrm{Cu}$ liquid. ${ }^{19}$ The broad diffuse and smooth peak that appears between $35^{\circ}$ and $40^{\circ}$ in the in situ XRD patterns of $\mathrm{Cu}$-doped samples after sintering for $1 \mathrm{~h}$ and $2 \mathrm{~h}$ (see Fig. $2 \mathrm{~b}$ and $2 \mathrm{c}$ ) confirms this opinion. It is worth noting that ball milling treatment can further improve the efficiency of $\mathrm{Cu}$ activated sintering of $\mathrm{MgB}_{2}$ at low temperatures. Thus, the reaction between $\mathrm{Mg}$ and $\mathrm{B}$ is finished after $\mathrm{Cu}$ activated sintering for only $2 \mathrm{~h}$ in the milled $\mathrm{MgB}_{2}$ samples. Look at Fig. 2 more carefully, the phase evolution undergoes different routes during the in situ $\mathrm{Cu}$ activated sintering process for the samples milled for $5 \mathrm{~h}$ and $10 \mathrm{~h}$, especially after sintering for $2 \mathrm{~h}$. For $5 \mathrm{~h}$-milled sample, after sintering for $2 \mathrm{~h}$, there is no obvious change in the phase composition. But in the $10 \mathrm{~h}$-milled sample, the intensity of both $\mathrm{MgO}$ peaks and $\mathrm{MgCu}_{2}$ peaks are gradually increased as sintering time increasing from $2 \mathrm{~h}$ to $5 \mathrm{~h}$. This result implies that after milling for $10 \mathrm{~h}$ the $\mathrm{Mg}$ particles become more active, and during the subsequent sintering process they can more easily react with residual $\mathrm{O}$ in the protected argon gas and $\mathrm{Cu}$, forming more $\mathrm{MgO}$ and $\mathrm{MgCu}_{2}$, respectively.

Whether these impurities such as $\mathrm{MgO}$ and $\mathrm{MgCu}_{2}$ can serve as flux pinning centers mainly depends on their size and microstructure distribution in the $\mathrm{MgB}_{2}$ matrix. Fig. 3 shows SEM images of sintered samples. It was observed that the $\mathrm{MgB}_{2}$ grains in the milled $\mathrm{MgB}_{2}$ samples prepared by $\mathrm{Cu}$-activated sintering at low temperature were much smaller and less regular than those in the reference $\mathrm{MgB}_{2}$ sample prepared by sintering at high temperature (see Fig. 3a, 3b, and 3c). ${ }^{2}$ Moreover, in the milled samples, the $\mathrm{MgB}_{2}$ grains contact each other tightly with fewer voids distributed within them and it is difficult to recognize single regular $\mathrm{MgB}_{2}$ grains among these $\mathrm{MgB}_{2}$ grains. These results are mainly attributed to the milling treatment of original powder and the suppression of volatilization of $\mathrm{Mg}$ during the low-temperature sintering process. In the $10 \mathrm{~h}$-milled sample sintered at low temperature, there are many nanoimpurities (the white dots marked by black arrows with size of about 5-10 nm, see Fig. 3c) embedded within the $\mathrm{MgB}_{2}$ grains. This is quite different from the microstructure of the reference and $5 \mathrm{~h}$-milled samples. Combined with the in situ XRD results (see Fig. 2c), these nanoimpurities can be identified as $\mathrm{MgO}$ or $\mathrm{MgCu}_{2}$. The size of these nanoimpurities is comparable to the coherence length of $\mathrm{MgB}_{2}$ and thus could serve as flux pinning centers. After observing Fig. 3c carefully, small $\mathrm{MgB}_{2}$ grains (about 50 $100 \mathrm{~nm}$ ) found to arrange in ordered and lamellar grains can be recognized unexpectedly (see the typical regions marked by white squares in Fig. 3c).

The microstructure of these lamellar nano grains was further investigated by HRTEM in detail and the corresponding images are shown in Fig. 4. It can be seen from Fig. 4a that the $\mathrm{MgB}_{2}$ matrix has an obvious layered structure. The planar distance of the lamellar $\mathrm{MgB}_{2}$ matrix is $0.213 \mathrm{~nm}$ (see Fig. 4b), which corresponds to [101] $\mathrm{MgB}_{2}$, the theoretical first preferentially growing crystal plane of $\mathrm{MgB}_{2}$ during sintering. The formation of these lamellar nano grains should be associated with the presence of local $\mathrm{Mg}-\mathrm{Cu}$ liquid at sintering temperatures as low as $575^{\circ} \mathrm{C}$. Obviously, it is easier for $\mathrm{MgB}_{2}$ grains to grow in the preferentially growing crystal plane following the direction of
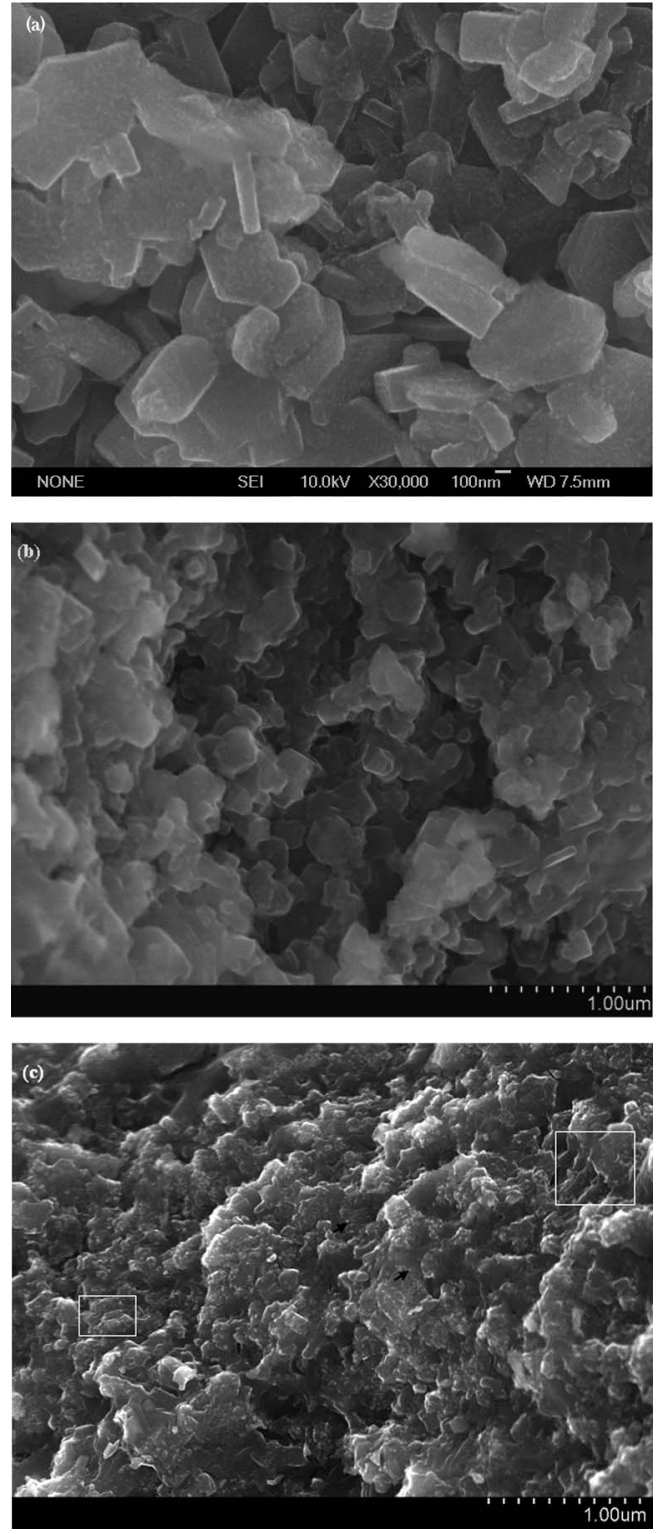

Fig. 3 SEM images of sintered samples with (a) reference $\mathrm{MgB}_{2}$ sample sintered at high temperature, (b) $5 \mathrm{~h}$-milled $\mathrm{MgB}_{2}$ sample fabricated by $\mathrm{Cu}$ activated sintering at low temperature and (c) 10 h-milled $\mathrm{MgB}_{2}$ sample fabricated by $\mathrm{Cu}$ activated sintering at low temperature.

local $\mathrm{Mg}-\mathrm{Cu}$ liquid than other directions without $\mathrm{Mg}-\mathrm{Cu}$ liquid. Besides, the ball milling treatment can further improve $\mathrm{Cu}$ activated sintering efficiency of $\mathrm{MgB}_{2}$ as well as refine the $\mathrm{MgB}_{2}$ grains. As a result, lamellar nano $\mathrm{MgB}_{2}$ grains are formed at a low sintering temperature. One can also recognize that there is a nanoparticle with a diameter of about $8 \mathrm{~nm}$ embedded in the lamellar $\mathrm{MgB}_{2}$ matrix, marked by a white arrow in Fig. $4 \mathrm{~b}$. This result is consistent with the SEM image in Fig. 3c, which both confirm the existence of nanoimpurities that can serve as flux pinning centers.

Based on the above microstructure observations, the morphology of the milled sample prepared by $\mathrm{Cu}$ activated sintering at low temperature is quite different from the typical morphology of the reference standard $\mathrm{MgB}_{2}$ sample prepared by 

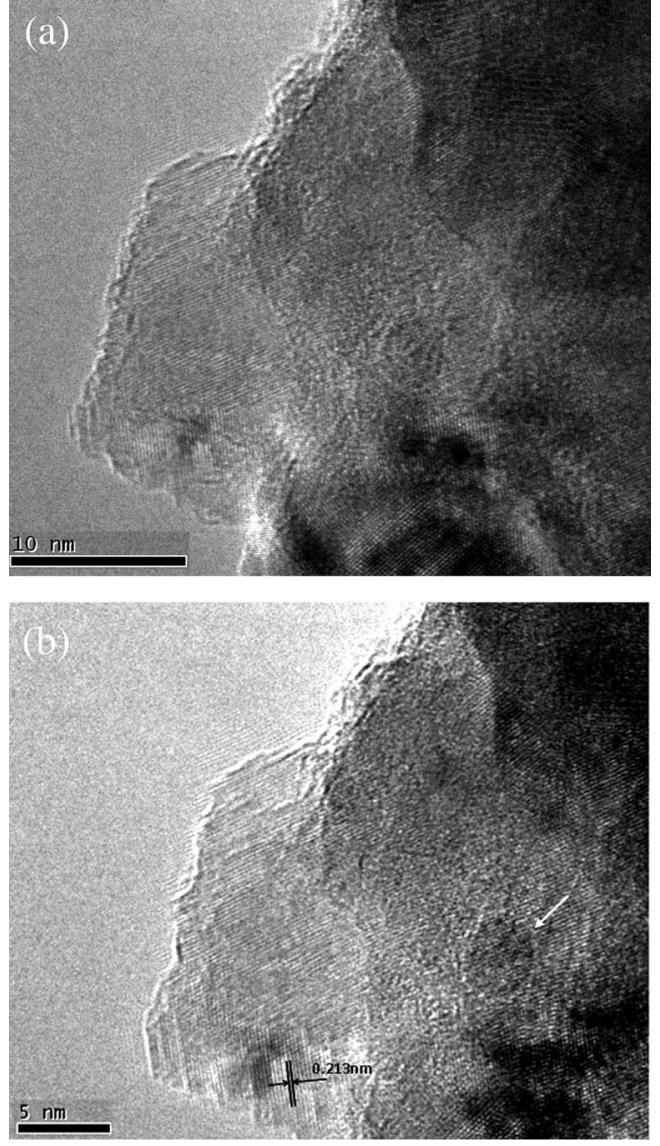

Fig. 4 The HRTEM image of lamellar nano $\mathrm{MgB}_{2}$ grains in the $10 \mathrm{~h}$ milled $\mathrm{MgB}_{2}$ sample fabricated by $\mathrm{Cu}$ activated sintering at low temperature.

sintering at high temperature. This unique morphology should significantly influence the performance of $J_{\mathrm{c}}$.

Measured $J_{\mathrm{c}}-H$ characteristics of the reference $\mathrm{MgB}_{2}$ prepared by sintering at high temperature and milled samples prepared by

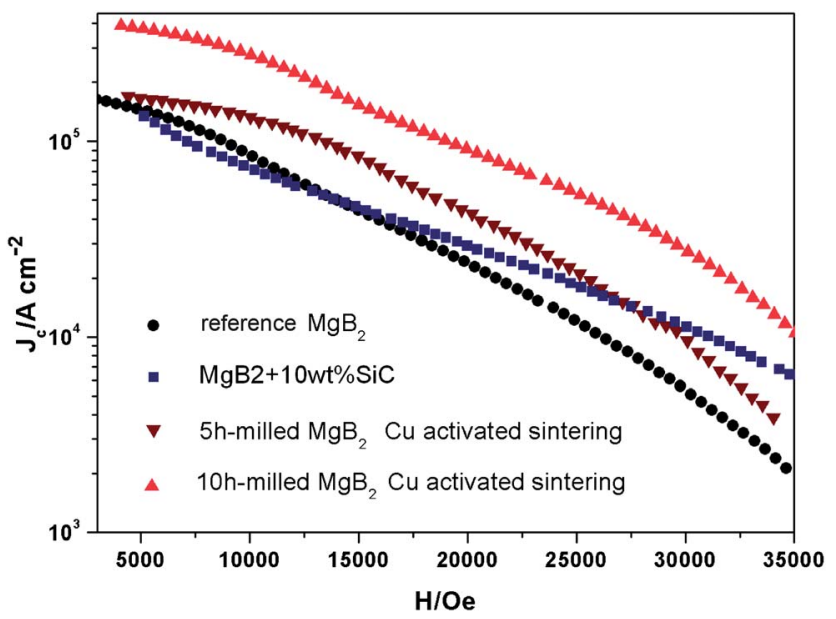

Fig. 5 At $20 \mathrm{~K}$, measured $J_{\mathrm{c}}-H$ characteristics of the reference $\mathrm{MgB}_{2}$ prepared by sintering at high temperature and milled samples prepared by $\mathrm{Cu}$ activated sintering at low temperature.
$\mathrm{Cu}$ activated sintering at low temperature are shown in Fig. 5. Besides, the $J_{\mathrm{c}}-H$ curve of nano SiC-doped samples was also given in Fig. ${ }^{20}{ }^{20}$ It was found that milled $\mathrm{MgB}_{2}$ samples prepared by $\mathrm{Cu}$ activated sintering at low temperature exhibit an excellent $J_{\mathrm{c}}$ that is much higher than that of the reference $\mathrm{MgB}_{2}$ sample sintered at high temperature. At self-field and low fields (below $2.5 \mathrm{~T}$ ), the $10 \mathrm{~h}$-milled samples are much higher than that of the reference and SiC-doped $\mathrm{MgB}_{2}$ samples sintered at high temperature (see Fig. 5). ${ }^{6,10,20}$ This is superior to the results obtained from SiC-doped samples sintered at high temperature, which generally underwent notable degradation in the $J_{\mathrm{c}}$ at low fields compared to pure $\mathrm{MgB}_{2}$ samples., ${ }^{6,10,21}$ In previous studies, ${ }^{19,22,23}$ minor $\mathrm{Cu}$ doping was found to enhance $J_{\mathrm{c}}$ of $\mathrm{MgB}_{2}$ superconductors at low fields. Compared to these $\mathrm{Cu}$ doped $\mathrm{MgB}_{2}$ samples prepared by sintering at low temperature and high temperature, ${ }^{19,22,23}$ the $10 \mathrm{~h}$-milled sample prepared by $\mathrm{Cu}$ activated sintering at low temperature in the present work still possesses higher $J_{\mathrm{c}}$ at low fields. This result should be related to the higher density and the presence of lamellar $\mathrm{MgB}_{2}$ grains in the 10 h-milled sample (see Fig. 3c and Fig. 4), which could effectively improve the grain connectivity of $\mathrm{MgB}_{2}$. Hereby, in order to investigate the grain connectivity of prepared samples in the present work, the temperature dependence of resistivity in the sintered samples was measured and the results are given in Fig. 6.

Both the $10 \mathrm{~h}$-milled sample and the reference sample prepared in the present work exhibit high $T_{\mathrm{c}}(38 \mathrm{~K})$, which is comparable to that of standard $\mathrm{MgB}_{2}$ bulk ${ }^{1}$ (see Fig. 6). According to the Rowell connectivity analysis, the calculated active crosssectional area fraction $\left(A_{\mathrm{F}}\right)$ represents the connectivity factor between adjacent grains. ${ }^{16,24}$ Here the $A_{\mathrm{F}}$ is estimated as:

$$
\begin{gathered}
A_{\mathrm{F}}=\Delta \rho_{\text {ideal }} /\left(\rho_{300 \mathrm{~K}}-\rho_{40 \mathrm{~K}}\right) \\
\Delta \rho_{\text {ideal }}=\rho_{\text {ideal }(300 \mathrm{~K})}-\rho_{\text {ideal }(40 \mathrm{~K})}
\end{gathered}
$$

Where $\rho_{\text {ideal }}$ is the resistivity of a reference crystal and $\rho_{T}$ is our measured resistivity at temperature $T$. here the $\Delta \rho_{\text {ideal }}$ is $7.3 \mu \Omega$ $\mathrm{cm}$, according to previous study. ${ }^{16,21}$

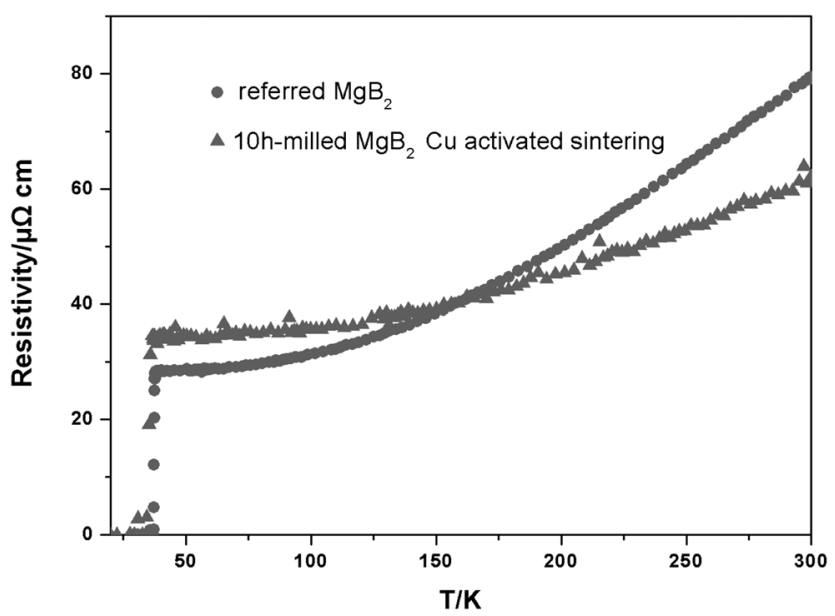

Fig. 6 The temperature dependence of resistivity of the reference $\mathrm{MgB}_{2}$ prepared by sintering at high temperature and $10 \mathrm{~h}$-milled samples prepared by $\mathrm{Cu}$ activated sintering at low temperature. 
Accordingly, the calculated $A_{\mathrm{F}}$ is about 0.30 and 0.20 for $10 \mathrm{~h}$ milled sample and reference $\mathrm{MgB}_{2}$ sample, respectively. This result indicates that the $10 \mathrm{~h}$-milled $\mathrm{MgB}_{2}$ sample fabricated by $\mathrm{Cu}$ activated sintering possesses much better grain connectivity than the reference $\mathrm{MgB}_{2}$ sample fabricated by traditional sintering. Hence, it is not difficult to explain why the $J_{\mathrm{c}}$ of $10 \mathrm{~h}$ milled $\mathrm{MgB}_{2}$ sample fabricated by $\mathrm{Cu}$ activated sintering is much higher than that of the reference $\mathrm{MgB}_{2}$ sample. Since the $10 \mathrm{~h}$ milled $\mathrm{MgB}_{2}$ sample contains many more impurities $(\mathrm{MgO}$ and $\mathrm{MgCu}_{2}$ ) that could depress the grain connectivity of $\mathrm{MgB}_{2}$ than the reference $\mathrm{MgB}_{2}$ sample, ${ }^{12}$ and it was previously reported that ball milling treatment of original powders could obviously decrease the grain connectivity of the final sintered $\mathrm{MgB}_{2}$ sample, ${ }^{16}$ the grain connectivity of $10 \mathrm{~h}$-milled $\mathrm{MgB}_{2}$ sample ought to have been worse than that of the reference $\mathrm{MgB}_{2}$ sample. From this view, the abnormal-but-excellent grain connectivity of the $10 \mathrm{~h}$-milled sample in the present work must be mainly attributed to the presence of lamellar nano $\mathrm{MgB}_{2}$ grains and higher sintering density.

Looking back at Fig. 5, at middle and relatively high fields (from $2.5 \mathrm{~T}$ to $3.5 \mathrm{~T}$ ), the level of enhancement in $J_{\mathrm{c}}$ of $10 \mathrm{~h}$ milled samples is even higher than that of SiC-doped samples sintered at high temperature. ${ }^{20}$ This can be mainly attributed to the presence of lots of nano $\mathrm{MgB}_{2}$ grain boundary pinning centers and nano impurity pinning centers in this sample (see Fig. 3c). In addition, as mentioned above, the excellent grain connectivity in this sample has also contributed to the improved $J_{\mathrm{c}}$ at middle and high fields.

Further analysis of flux pinning behavior in terms of the flux pinning force provides us with deeper insights. Fig. 7 shows the normalized pinning force $F_{\mathrm{p}} / F_{\mathrm{pmax}}$ as a function of a reduced magnetic field $h$ in the prepared samples with $h=H / H_{\text {irr }}$. The irreversibility field $\left(H_{\text {irr }}\right)$ has been estimated by extrapolating the $J_{\mathrm{c}}^{1 / 2} H^{1 / 4}$ vs. $H$ curve to the horizontal axis, also called the Krammer extrapolation. Flux pinning curves for the $10 \mathrm{~h}$ milled samples prepared by $\mathrm{Cu}$ activated sintering at low temperature are shifted to the right compared to the reference

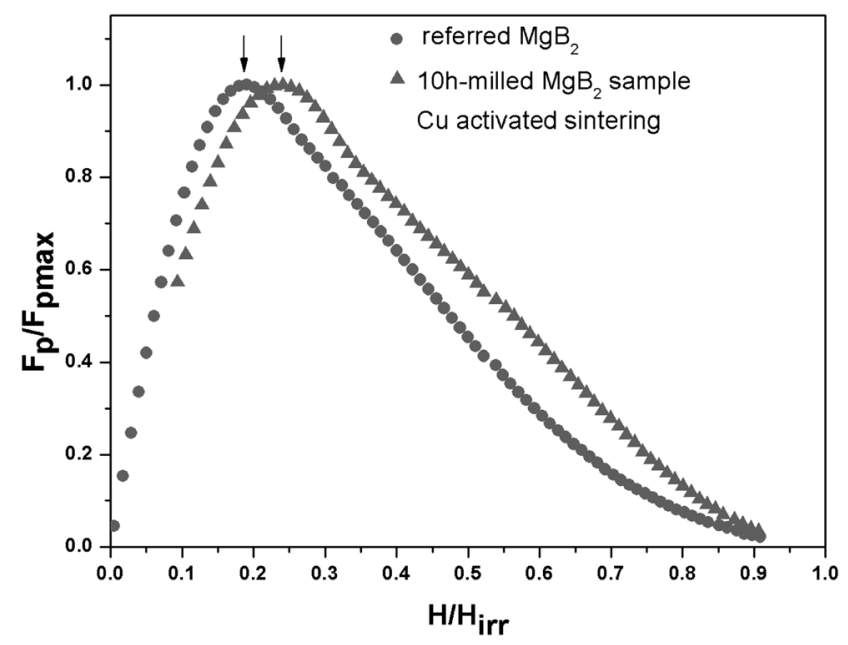

Fig. 7 The normalized pinning force $F_{\mathrm{p}} / F_{\mathrm{p}_{\max }}$ as a function of reduced magnetic field $h$ in the reference $\mathrm{MgB}_{2}$ sample prepared by sintering at high temperature and $10 \mathrm{~h}$-milled samples prepared by $\mathrm{Cu}$ activated sintering at low temperature with $h=H / H_{\text {irr }}$.
$\mathrm{MgB}_{2}$ sample. The clear shift of the peak of the pinning force curve towards higher field reveals the additional pinning centers in this sample besides grain boundary pinning. As described earlier, $\mathrm{MgO}$ and $\mathrm{MgCu}_{2}$ nanoimpurities with a size comparable to the coherence length of $\mathrm{MgB}_{2}$ can act as pinning centers, which is the main reason for the shift in the $F_{\mathrm{p}} / F_{\mathrm{pmax}} v s$. $H$ curve towards higher field. It can be also seen from Fig. 7 that for the $10 \mathrm{~h}$-milled sample the peak is broader than the reference sample, indicating a higher pinning strength is for this sample; this is confirmation of the $J_{\mathrm{c}}$ result. In the present case it is seemingly the combination of grain boundary pinning and nanoimpurity pinning.

\section{Conclusions}

$\mathrm{MgB}_{2}$ samples consisting of lamellar nano $\mathrm{MgB}_{2}$ grains containing many dispersed nanoimpurities were prepared by a ball milling treatment of the original powder and subsequent $\mathrm{Cu}$ activated sintering at a low temperature. The higher sintering density and lamellar $\mathrm{MgB}_{2}$ grains in the present sample exhibit better grain connectivity than the typical morphology of $\mathrm{MgB}_{2}$ samples prepared by the traditional high-temperature sintering. Additionally, lots of nano $\mathrm{MgB}_{2}$ grain boundaries and nano impurities in the prepared sample can obviously increase flux pinning centers. Both of these factors contribute to the significant improvement in $J_{\mathrm{c}}$ from low field to relative high field. From this point of view, the method developed here is an effective way of both improving the grain connectivity of $\mathrm{MgB}_{2}$ and increasing flux pinning centers. Hence, it is also a promising and low-cost way to further improve the $J_{\mathrm{c}}$ of $\mathrm{MgB}_{2}$ superconductors across the entire applied magnetic range without using expensive nanometer-sized dopants.

\section{Acknowledgements}

The authors are grateful to the National Natural Science Foundation of China (Grant No. 51077099), the Program for New Century Excellent Talents in University and the Seed Foundation of Tianjin University for grant and financial support.

\section{References}

1 J. Nagamatsu, N. Nakagawa, T. Muranaka, Y. Zentani and J. Akimitsu, Nature, 2001, 410, 63-64.

2 Z. Q. Ma and Y. C. Liu, Int. Mater. Rev., 2011, 56, 267-286.

3 Y. Bugoslavsky, L. F. Cohen, G. K. Perkins, M. Polichetti, T. J. Tate, R. Gwilliam and A. D. Caplin, Nature, 2001, 411, 561-563.

4 M. Eisterer, M. Zehetmayer, S. Tonies, H. W. Weber, M. Kambara, N. H. Babu, D. A. Cardwell and L. R. Greenwood, Supercond. Sci. Technol., 2002, 15, 1088.

5 J. S. Slusky, N. Rogado and K. A. Regan, Nature, 2001, 410, 343-345.

6 S. X. Dou, S. Soltanian, J. Horvat, X. L. Wang, S. H. Zhou, M. Ionescu and H. K. Liu, Appl. Phys. Lett., 2002, 81, 3419-3421.

7 S. Zhou, A. V. Pan, D. Wexler and S. X. Dou, Adv. Mater., 2007, 19, $1373-1376$.

8 A. Vajpayee, V. P. S. Awana, G. L. Bhalla and H. Kishan, Nanotechnology, 2008, 19, 125708.

9 Z. Q. Ma, Y. C. Liu, Y. J. Han, Q. Zhao and Z. M. Gao, J. Appl. Phys., 2008, 104, 063917.

10 W. K. Yeoh, J. H. Kim, J. Horvat, S. X. Dou and P. Munroe, Supercond. Sci. Technol., 2006, 19, 596.

11 C. Shekhar, R. Giri, R. S. Tiwari, O. N. Srivastava and S. K. Malik, J. Appl. Phys., 2007, 101, 043906.

12 A. Gumbel, J. Eckert, G. Fuchs, K. Nenkov, K.-H. Muller and L. Schultz, Appl. Phys. Lett., 2002, 80, 2725-2727. 
13 M. Herrmann, W. Haessler, C. Rodig, W. Gruner, B. Holzapfel and L. Schultz, Appl. Phys. Lett., 2007, 91, 082507.

14 Z. Q. Ma, Y. C. Liu, J. Huo and Z. M. Gao, J. Appl. Phys., 2009, 106, 113911.

15 X. Xu, J. H. Kim, M. S. A. Hossain, J. S. Park, Y. Zhao, S. X. Dou, W. K. Yeoh, M. Rindfleisch and M. Tomsic, J. Appl. Phys., 2008, 103, 023912 .

16 J. M. Rowell, S. Y. Xu, X. H. Zeng, A. V. Pogrebnyakov, Q. Li, X. X. Xi, J. M. Redwing, W. Tian and X. Pan, Appl. Phys. Lett., 2003, 83, 102.

17 A. Yamamoto, J. Shimoyama, S. Ueda, Y. Katsura, S. Horii and K. Kishio, Supercond. Sci. Technol., 2005, 18, 116.

18 A. Yamamoto, J. Shimoyama, S. Ueda, Y. Katsura, I. Iwayama, S. Horii and K. Kishio, Phys. C, 2006, 445-448, 801.
19 Z. Q. Ma, Y. C. Liu, Q. Z. Shi, Q. Zhao and Z. M. Gao, Supercond. Sci. Technol., 2008, 21, 065004.

20 Z. Q. Ma, Y. C. Liu, Q. Zhao, Z. Z. Dong and L. M. Yu, Supercond. Sci. Technol., 2009, 22, 085015.

21 S. X. Dou, O. Shcherbakova, W. K. Yeoh, J. H. Kim, S. Soltanian, X. L. Wang, C. Senatore, R. Flukiger, M. Dhalle, O. Husnjak and E. Babic, Phys. Rev. Lett., 2007, 98, 097002.

22 Y. Hishinuma, A. Kikuchi, Y. Iijima, Y. Yoshida, T. Takeuchi and A. Nishimura, Supercond. Sci. Technol., 2006, 19, 1269-73.

23 Y. Kimishima, S. Takami, M. Uehara and T. Kuramoto, Phys. C, 2006, 445-448, 224-7.

24 P. C. Canfield, D. K. Finnemore, S. L. Bud'ko, J. E. Ostenson, G. Lapertot, C. E. Cunningham and C. Petrovic, Phys. Rev. Lett, 2001, 86, 2423-2426. 